\title{
An assessment of the health risks associated with shared sanitation: a case study of the community ablution blocks in Durban, South Africa
}

\author{
Preshod S. Ramlal • Johnson Lin • \\ Christopher A. Buckley • Thor Axel Stenström • \\ Isaac D. Amoah
}

Received: 29 May 2021 / Accepted: 22 January 2022 / Published online: 10 February 2022

(C) The Author(s), under exclusive licence to Springer Nature Switzerland AG 2022

\begin{abstract}
Shared sanitation facilities have been hailed as an innovative approach to solve the challenge with sanitation access. However, these facilities may act as hotspots for disease transmission due to unhygienic conditions. In this study we used quantitative (based on Escherichia coli contamination) techniques to assess the health risks associated with the use of community ablution blocks (CABs). The most contaminated surfaces were the cistern handle $\left(5.7 \log _{10}\right.$
\end{abstract}

We regret to state that Prof. C. Buckley passed away while this manuscript was under review.

Supplementary information The online version contains supplementary material available at https://doi. org/10.1007/s10661-022-09815-x.

P. S. Ramlal ( $\square)$

eThekwini Municipality Health Department, 9 Archie Gumede Place, 4001 Durban, South Africa

e-mail: preshramlal@gmail.com

\section{P. S. Ramlal · J. Lin}

School of Life Sciences, University of KwaZulu-Natal, KwaZulu-Natal, 4001 Durban, South Africa

C. A. Buckley

WASH Research and Development Centre, University of KwaZulu-Natal, KwaZulu-Natal, 4001 Durban, South Africa

T. A. Stenström · I. D. Amoah

Institute for Water and Wastewater Technology, Durban University of Technology, KwaZulu-Natal, Durban,

South Africa $\left.\mathrm{cfu} / \mathrm{cm}^{2}\right)$ and internal pull latch $\left(5.8 \log _{10} \mathrm{cfu} / \mathrm{cm}^{2}\right)$. Based on the E. coli contamination, at least two people out of $100 \mathrm{CAB}$ users might be potentially infected when they touch "hot" surfaces. These risks were modelled assuming transfer of potentially pathogenic E. coli from these surfaces to the mouth. The incorporation of risk-reduction measures, such as wiping of these surfaces or washing of hands, could potentially result in significant reduction of infection risks. The most significant risk-reduction intervention was determined to be wiping of the contact surfaces, especially twice prior to contact. A combination of risk-reduction interventions could further reduce the risks. This study shows that contamination of contact surfaces within shared CABs could lead to increased risks of infections, requiring measures aimed at reducing the associated risks. The risk assessment framework used in this study could therefore be applied in similar settings to estimate associated health risks with the use of such facilities.

Keywords Shared sanitation - Community ablution blocks · Microbial health risks · Quantitative microbial risk assessment $\cdot$ Risk reduction

\section{Introduction}

Shared sanitation can play a critical role in achieving sanitation coverage (Garn et al., 2017; Pickering et al., 2015). For many people living in densely populated 
urban areas, such as informal settlements, the alternative to open defecation is the use of shared sanitation (Busquet, 2015). However, despite the increase in the use of shared sanitation, there is divided opinion of its appropriateness. While some researchers contend that shared or public toilets (as opposed to individual household toilets) are the best option for densely populated urban slums due to space constraints (Katukiza et al., 2012; Schouten \& Mathenge, 2010), others have shown that shared sanitation may be a contributory factor to increased frequency of infections (Fenn et al., 2012; Heijnen et al., 2014; Patil et al., 2014; Pickering et al., 2015). This relates to increased risk of diarrhoea, soil-transmitted helminths (STHs), and trachoma (Guerrant et al., 2013) due to direct contamination of contact surfaces with pathogens. Airborne dissemination may also occur, where viruses and bacteria have been found on bathroom surfaces, during toilet flushing (Barker \& Bloomfield, 2000; Gerhardts et al., 2012). The ambient conditions in the sanitation environment are ideal for microorganism survival and proliferation, thereby increasing faecal-oral exposure (Kagan et al., 2002; Kay et al., 2006). Survival of microorganisms on surfaces such as plastics and metals has been reported extensively (Alsallaiy et al., 2016; Barker \& Bloomfield, 2000; Curtis et al., 2003; Neely \& Maley, 2000).

Furthermore, contamination of contact surfaces within shared sanitation facilities could be more frequent, with higher microorganism concentrations, than single-household facilities due to higher user numbers and frequency. This has led to several reports of shared sanitation acting as hotspots for diarrhoeal diseases (Baker et al., 2016; Crocker \& Bartram, 2016; Rah et al., 2015; Ramlal et al., 2019). Disease transmission in sanitation facilities could occur either through toilets-to-hands-to-mouth contact or from contaminated hands to surfaces (Barker \& Bloomfield, 2000; Curtis et al., 2003).

Private toilets will not always be cleaner than shared facilities (Ahmed et al., 2012) but the number of users may play a significant role in the cleanliness of these facilities (Günther et al., 2012). When the number of households were below 4 per facility, the cleanliness of shared facilities was comparable to private ones ( $80 \%$ clean), while the sharing of the facilities by more than 10 households resulted in $40 \%$ drop in cleanliness (Günther et al., 2012). In most settings where shared sanitation is practiced, the responsibility of cleaning is shared by the users or volunteers (Kwiringira, 2017). This has been reported to result in apathy towards the hygienic maintenance of these facilities (Kwiringira, 2017; Tumwebaze \& Mosler, 2015). Therefore, the employment of caretakers, living in the communities where shared sanitation facilities are located, like the community ablution blocks (CABs) in the informal settlements of the eThekwini Municipality, has been recommended as an alternative.

This study present the assessment of the health risks associated with the use of shared sanitation facilities, such as the CABs. The quantitative approach adopted in this study presents the assessment of potential health and safety risks associated with the use of shared sanitation facilities. This study aims to make a significant contribution by presenting techniques that can be used to estimate health risks associated with shared sanitation and possible mitigation measures that can be implemented to reduce the risks of infections.

\section{Methodology}

\section{Study location}

CABs located in two informal settlements in the eThekwini Municipality (Durban) of South Africa were selected for this study. Male and female CABs within these settlements were chosen and the health risks associated with its usage were determined based on the concentration of Escherichia coli on key contact surfaces within the CABs. The selected type of contact surfaces was based on recent studies in the field (Bohnert et al., 2016; Mpotane et al., 2013).

\section{Swab sampling for E. coli concentration}

The contact surfaces selected included cistern handle, toilet seat, floor surface in front of the toilet, internal pull latch of cubicle door, external door handle of cubicle, tap handle in shower cubicle, internal common floor surface, and tap in wash hand basin (Fig. 1). These contact surfaces were chosen based on recommendations made in studies by Mpotane et al. (2013) and Bohnert et al. (2016). Samples were taken with the LABOCARE $^{\mathrm{TM}}$ sterile swab sticks, with transport media (Amies), following the protocol 


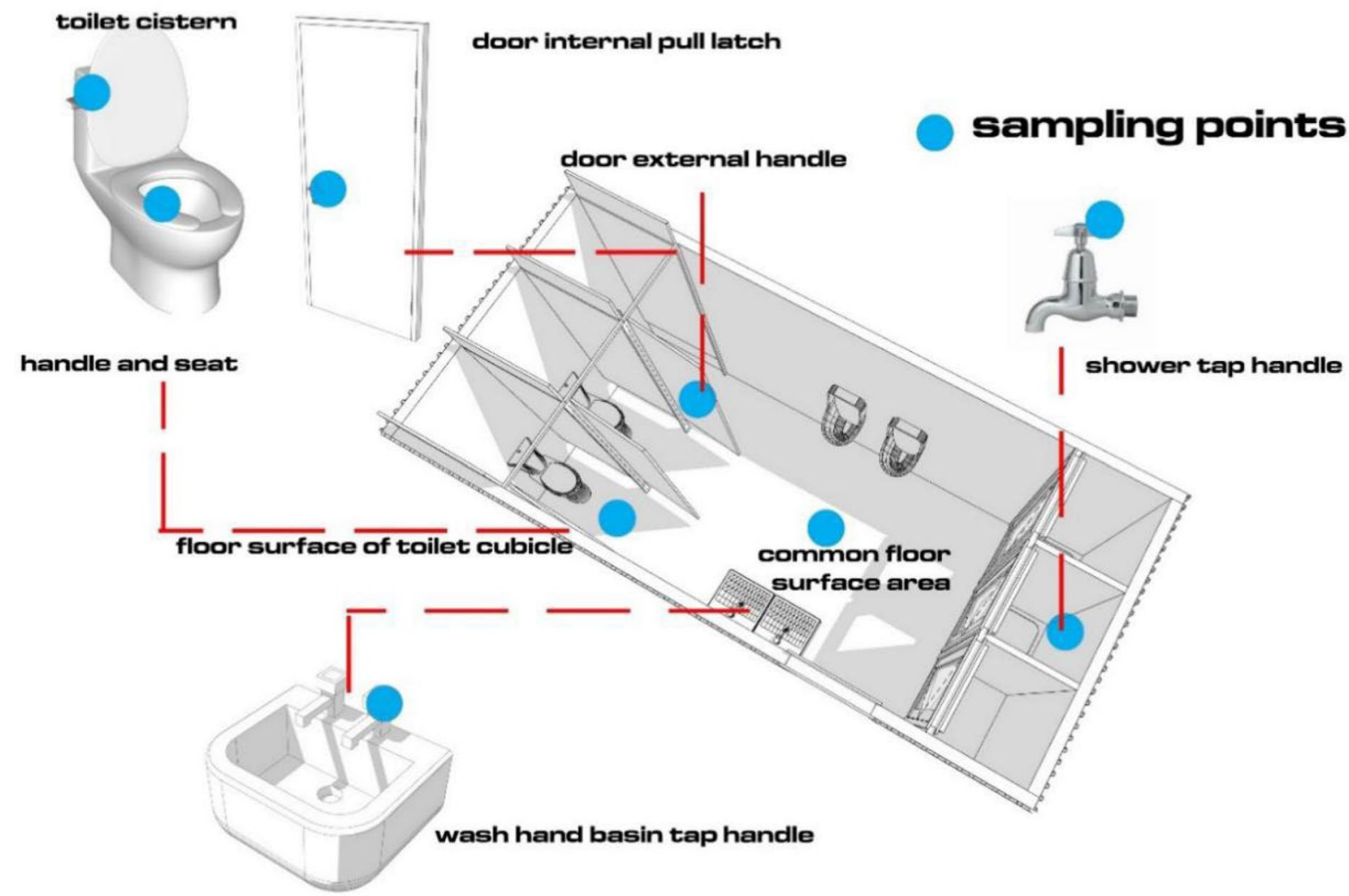

Fig. 1 Key contact surface areas swabbed to determine E. coli concentration within internal surfaces of CABs

proposed by Park et al. (2017). One cubicle each in the male and female $\mathrm{CAB}$ toilets was sampled on three different occasions over a period of one month.

Enumeration of $E$. coli

Aliquots of $0.1 \mathrm{~mL}$ of each sample were spread plated on agar plates containing specific media for $E$. coli (Chromocult media) after a serial of $10^{-4}$ to $10^{-10}$ dilutions. The plate lids were slightly left open after spread plating for 2-3 min to allow for sample absorption. Incubation was made at $37{ }^{\circ} \mathrm{C}$ for $24 \mathrm{~h}$. The area swabbed for each surface is presented in Table S1 (Appendix I) and used to calculate the concentration of E. coli per $\mathrm{cm}^{2}$ of surface area. Ten colonies per sampling site from the Chromocult agar plates were selected based on morphological characteristics and colour (Lange et al., 2013). These were confirmed biochemically using the IMVic test (Lupindu, 2017) and polymerase chain reaction (PCR) (Abid \& AL-zuwainy, 2015) where the uidA gene was used as the marker for the confirmation of $E$. coli isolates. The primers used are presented in Table S2
(Appendix I). For quality control, each analysis had an additional control, swab sticks taken through the sample analysis process but without actual swabbing. This was intended to ensuring that there was no contamination during the sample processing.

\section{Microbial infection risk assessment}

The risk of infection was calculated using the quantitative microbial risks assessment (QMRA) approach. This is an approach that combines mathematical equations with knowledge and information on microbial ecology, disease epidemiology, and transmission. This tool has been recommended as a useful technique in assessing the risks associated with bioaerosols, drinking water, reclaimed water, and irrigation water (Carducci et al., 2016; Ezzat, 2020; Girardi et al., 2019; Gularte et al., 2019; Petterson \& Ashbolt, 2016). It therefore could be adopted to provide an assessment approach for the use of shared toilets, such as the CABs. QMRA consists of four 
interrelated steps: (a) hazard identification; (b) exposure assessment; (c) dose-response assessment, and (d) risk characterization (Haas et al., 2014).

\section{Hazard identification}

The hazard of choice for this study was pathogenic $E$. coli. E. coli isolated from environmental samples could include non-pathogenic environmental strains and the mean $E$. coli counts per $\mathrm{cm}^{2}$ would therefore be relatively higher than the pathogenic strains. Therefore, the risk of infection was calculated assuming that $8 \%$ of average $E$. coli counts are pathogenic (George et al., 2013; Howard et al., 2006; Machdar et al., 2013). The pathogenic E. coli concentrations were then used as doses that were incorporated into the QMRA at the dose-response modelling stage to ascertain the risks.

\section{Exposure assessment}

The exposure scenarios used in the health risk assessment were contact with contaminated surfaces within the CABs. The frequency of exposure to these contaminated surfaces was determined based on the frequency of use of the CABs as provided by the respondents during this study. The exposure assessment framework is presented in Fig. 2.

\section{Dose-response assessment}

Several dose-response models have been developed for the estimation of risk posed by exposure to pathogenic E. coli. In this study, the beta-Poisson dose-response model was used (Haas et al., 2014). The beta-Poisson model is defined by the following equation:
Fig. 2 Scenario for assessing the exposure and possible risks associated with contamination of the contact surfaces (adapted from Ryan et al. (2014))

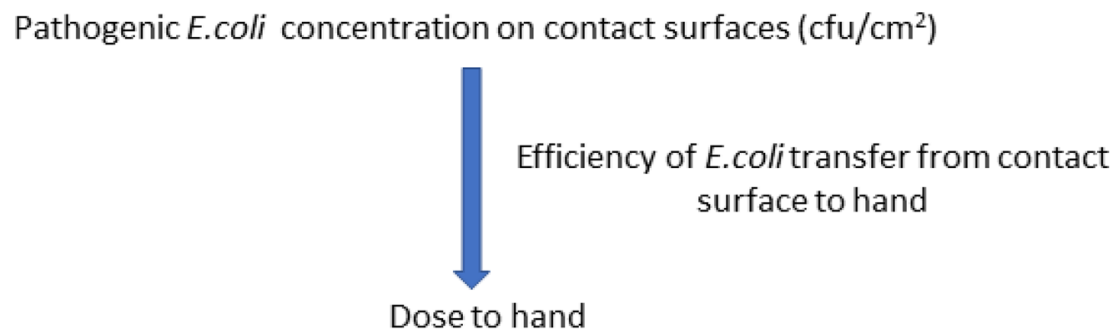

Efficiency of E.colitransfer from hand to lip/mouth

Dose to lip/eye/nose

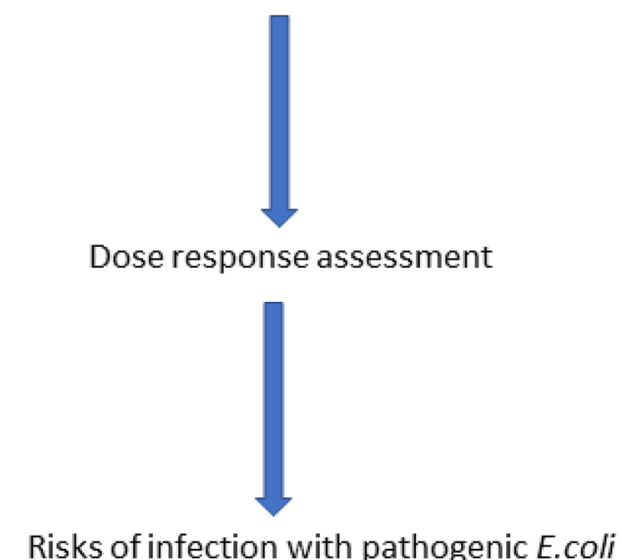

Risks of infection with pathogenic E.coli 
$p(d)=1-\left(1+\left(\frac{d}{N_{50}}\right)\left(2^{\frac{1}{\alpha}}-1\right)\right)^{-\alpha}$

With $p(d)$ being the risk of infection and " $d$ " the total concentration of pathogenic $E$. coli ingested (Haas et al., 2014). $N_{50}$ is the median infection dose representing the number of organisms that will infect $50 \%$ of the exposed population and $\alpha$ the dimensionless infectivity constant. The input values for $N_{50}$ and $\alpha$ are presented in Table 1. The dose of pathogenic $E$. coli ingested was calculated based on the concentration of $E$. coli measured on the contact surfaces. This considered that about $8 \%$ of total E. coli are pathogenic. Probability distribution functions (PDFs) were fitted to the concentration of pathogenic E. coli using @ Risk (Palisade Inc., USA) with the best distribution selected based on the Akaike information criterion (AIC). The dose of $E$. coli ingested via the framework presented in Fig. 2 was then determined by accounting for the fraction of the bacterial load on the surfaces that will be transferred to the hands and the fraction on these bacteria that will eventually be transferred to the mouth/lips. The transfer efficiency from contact surfaces to hands and hands to mouth/lips was modelled using the input values presented in Table 1.

\section{Risk characterization}

In the risk characterization, all the outcomes of the hazard identification, exposure assessment, and dose-response assessment were combined to characterize the infection risks for exposed individuals. The risk of infection associated with multiple exposures $[P 1(A)]$ was determined using the following formula:
$P 1(A)=1-(1-P(d))^{n}$

where $P(d)$ is the risk of infection from a single exposure to a dose $d$ of the pathogen, calculated using the beta-Poisson dose-response model presented above; and $n$ being the number of times/days of exposure to the single dose $d$ (Sakaji \& Funamizu, 1998). Two different multiple exposure scenarios were considered, daily and yearly exposures. To determine the risks of infection from multiple exposures within a day, a user frequency survey was conducted as part of a larger household questionnaire. Inhabitants of the two settlements were asked how many times they used these CABs within a day. This gives information on the number of times the users could potentially be exposed to the pathogen. This survey led to modelling the exposures per day with a uniform distribution of a minimum of 1 and maximum of 2 times per day. The yearly exposure risks were modelled assuming that the CABs are used every day of the year; therefore, an $n$ value of 365 was used to calculate the yearly risks. The outcome of the daily risks was used as input for the $P(d)$ in this case to determine the yearly risks.

Potential impact of risk-reduction measures on infection risks

The potential reduction in risks of infection after implementation of risks reduction measures was also determined. Five risk-reduction interventions were considered in this study; these can be further grouped into three categories: wiping of contact surfaces, washing of hands (for at least $20 \mathrm{~s}$ ), and a combination of these interventions. The various interventions considered were the following:

Table 1 Input values for the dose calculation and dose-response modelling

\begin{tabular}{lll}
\hline Parameter & Input value & Reference \\
\hline Bacterial transfer from contact surface to hands & Uniform distribution $(0.13 ; 0.38)$ & Ryan et al., 2014 \\
Bacterial transfer from hands to mouth/lips & Median value $(0.41)$ & Girardi et al., 2019 \\
$\boldsymbol{N}_{\mathbf{5 0}}$ & $2.11 \times 10^{6}$ & \\
$\alpha$ & $1.55 \times 10^{-1}$ & Tuladhar et al., 2012 \\
Pathogen reduction after one wipe of surfaces & Median value $\left(1 \log _{10}\right)$ & Jensen et al., 2015 \\
Pathogen reduction after two wipes of surfaces & Uniform distribution $\left(1 ; 3 \log _{10}\right)$ & Uniform distribution $\left(0.6 ; 1.4 \log _{10}\right)$ \\
Pathogen reduction achieved with washing of hands without soap & Uniform distribution $\left(0.9 ; 2.5 \log _{10}\right)$ & \\
Pathogen reduction achieved with washing of hands with soap & . & \\
\hline
\end{tabular}


1. Wiping of contact surfaces once: According to Tuladhar et al. (2012) a simple wipe of surfaces with soap may lead to $1 \log _{10}$ reduction in bacterial concentration.

2. Wiping of contact surfaces twice: A second wipe could potentially further reduce the bacterial concentration by $1-3 \log _{10}$.

3. Hand washing with soap: Jensen et al. (2015) reported that washing of hands with soap could achieve a $1.7( \pm 0.8) \log _{10}$ reduction of pathogens.

4. Hand washing without soap: Washing without the use of soap could potentially result in $1.0( \pm 0.4)$ $\log _{10}$ reduction.

5. Combination of risk-reduction interventions: The combined effect of wiping of the contact surfaces once and washing of hands without soap was also modelled. These two risks reduction measures were chosen based on the interventions that require the least effort and resources.

The input values used for modelling the risks reduction are presented in Table 1. All risk models were subjected to Monte Carlo simulations of 10,000 iterations for the probability of infections. These models were constructed using the @Risk 7.5 (Palisade Corporation, USA) software add-on to Excel (Microsoft Cooperation, USA).

\section{Statistical analysis}

Comparison of the concentration of E. coli on the various surfaces and the associated risk was performed with the Kruskal-Wallis test followed by Dunn's post-test at a 95\% confidence interval (Dinno, 2015). Determination of the statistical significance of the risk-reduction measures was performed with the Mann-Whitney U test. All these comparative statistical analyses were performed using GraphPad Prism (version 7).

\section{Results}

Quantitative assessment of risks from contact with surfaces within the CABs

\section{E. coli concentration on contact surfaces in the $C A B S$}

E. coli concentration on the contact surfaces varied, although not significantly. Irrespective of the study location, the highest concentration of E. coli was detected on contact surfaces within the female toilets (Fig. 3). The highest concentration of E. coli was on the cistern handle $\left(6.01 \log _{10} \mathrm{cfu} / \mathrm{cm}^{2}\right)$, floor surface in front of toilet $\left(6.23 \log _{10} \mathrm{cfu} / \mathrm{cm}^{2}\right)$, and tap handle $\left(6.25 \log _{10} \mathrm{cfu} / \mathrm{cm}^{2}\right)$, all within female toilets (Fig. S1, Appendix I). The difference between the male and female toilets in relation to the concentration of $E$. coli was statistically significant ( $p$-value $\leq 0.05$ ), on the following surfaces irrespective of sampling location; cistern handle, floor surface in front of toilet, and tap handle in wash basin. However, in some instances the statistically significant differences between the female and male toilets were only observed in one settlement (sampling location) (Fig. 3).

Comparing the different surfaces irrespective of gender, using the toilet and location, the highest mean concentration of $E$. coli was detected on the cistern handle $\left(5.7 \log _{10} \mathrm{cfu} / \mathrm{cm}^{2}\right)$, internal pull latch $(5.8$ $\left.\log _{10} \mathrm{cfu} / \mathrm{cm}^{2}\right)$, external door handle $\left(5.7 \log _{10} \mathrm{cfu} /\right.$ $\mathrm{cm}^{2}$ ), and tap handle in shower cubicle (5.7 $\log _{10} \mathrm{cfu} /$ $\mathrm{cm}^{2}$ ) (Fig. 3). The Mann-Whitney tests showed a statistically significant difference $(p$-value $\leq 0.05)$ in $E$. coli concentrations between the cistern handle and

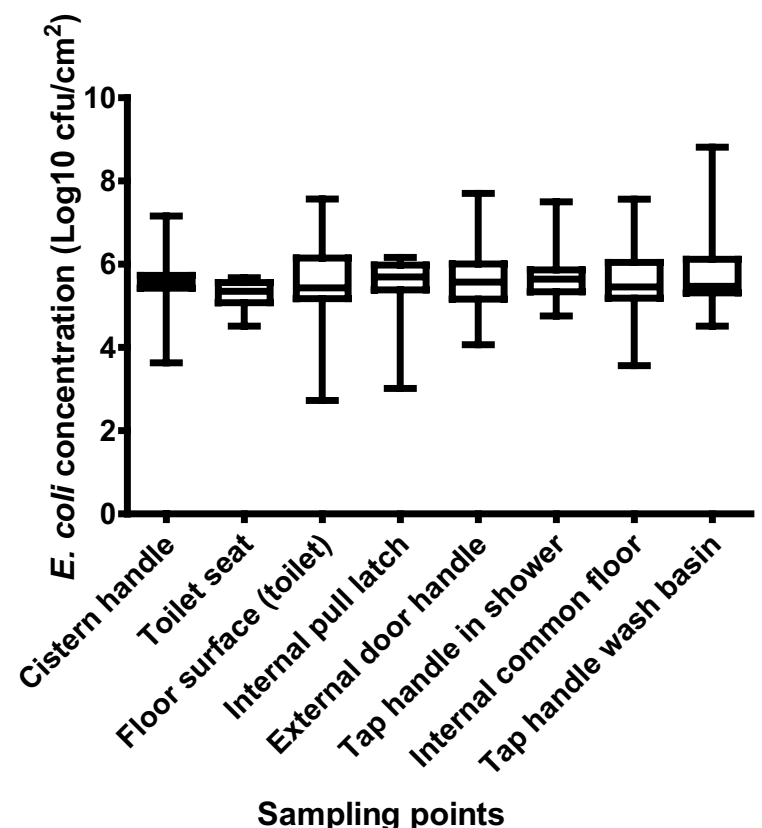

Fig. 3 Concentration of E. coli on key contact surfaces in community ablution blocks (CABs) within the two settlements 
toilet seat, the toilet seat and internal pull latch, and between the toilet seat and tap handle in shower.

Potential risks of infection with pathogenic $E$. coli on the contact surfaces before and after incorporation of risk-reduction measures

The potential risks of infection with pathogenic $E$. coli based on the concentration on these contact surfaces varied in a similar fashion to the variation in the E. coli concentration measured and presented in Fig. 3. Table 2 presents the calculated median risks of infection. Briefly, considering only daily risks, at least two people out of 100 users of the CABs may be infected when they touch surfaces such as the cistern handle, internal pull latch, external door handle, and the tap handles in both the shower and wash basin $\left(10^{-2}\right)$ (Table 2). However, the highest risk of infection was determined to be contact with the internal pull latch $\left(2.5 \times 10^{-2}\right)$. Based on the earlier user survey conducted in the study areas, it was observed that the populations within these informal settlements use the CABs up to twice a day. We modelled the frequency of exposure in a day and assessed the risks thereof (daily risks). The daily risks of infection were higher than the one-time exposure risks reported; for instance, the risks of infection after contact with the internal pull latch increased to almost four out of 100 people exposed being infected, compared to the almost three out of 100 for one-time exposure. This increase in risk of infection was also observed for contact with the rest of the other contact surfaces (Table 2). Multiple exposures over the course of the year may also lead to a statistically significant increase in the risks of infection with pathogenic E. coli. As shown in Table 2, yearly exposure may result in almost every person who touches these surfaces been infected. This is due to the measured risks of either 1 or $9.9 \times 10^{-1}$ per person per year; with the exception of the floor surface in front of the toilet cubicle, which had a risk of infection of $8.6 \times 10^{-1}\left( \pm 6.1 \times 10^{-3}\right)$ per person per year.

Potential risk reduction based on hypothetical risk-reduction measures

Implementation of risk-reduction measures, such as cleaning of the surfaces and washing of hands with and without soap, could potentialy reduce the risks as calculated. For instance, wiping of the internal pull latch surfaces could potentially lead torisk estimates of $2.2 \times 10^{-2}\left( \pm 3.1 \times 10^{-4}\right)$, compared to $2.5 \times 10^{-2}\left( \pm 3.0 \times 10^{-4}\right)$ for the uncleaned surfaces. Wiping of the surfaces twice reduced the risks further but not significantly. Furthermore, washing of hands without soap reduced the risks to $2.4 \times 10^{-2}$ $\left( \pm 3.0 \times 10^{-4}\right)$ after contact with the internal pull latch. Washing of hands without soap also reduces the risks as well (Fig. 4). Comparatively, wiping the surface twice achieves the highest reduction of risks among the four singular risk interventions modelled. Wiping the surface once achieves similar risk reduction compared to wiping the surfaces twice. Combining one wipe of the contact surfaces with hand washing without soap reduces the risks further; however, these risk estimates are not significantly lower than the risks when the surfaces are cleaned (Fig. 4). Detailed information on the calculated risks are presented in Appendix I (Table S3).

\section{Discussion}

\section{Contamination of contact surfaces with $E$. coli}

The detection of E. coli on almost all key contact surfaces in our study shows the potential for these surfaces

Table 2 Calculated median risk of infection $( \pm 90 \% \mathrm{CI})$ with pathogenic $E$. coli due to one-time, daily, and yearly exposure to the contact surfaces within the CABs

\begin{tabular}{|c|c|c|c|c|c|c|c|c|}
\hline & Cistern handle & Toilet seat & $\begin{array}{l}\text { Floor surface in } \\
\text { front of toilet }\end{array}$ & $\begin{array}{l}\text { Internal pull } \\
\text { latch }\end{array}$ & $\begin{array}{l}\text { External door } \\
\text { handle }\end{array}$ & $\begin{array}{l}\text { Tap handle in } \\
\text { shower cubicle }\end{array}$ & $\begin{array}{l}\text { Internal common } \\
\text { floor surface }\end{array}$ & $\begin{array}{l}\text { Tap handle in } \\
\text { wash basin }\end{array}$ \\
\hline One time & $\begin{array}{l}1.9 \times 10^{-2} \\
\left( \pm 7.1 \times 10^{-4}\right)\end{array}$ & $\begin{array}{l}1.1 \times 10^{-2} \\
\left( \pm 1.4 \times 10^{-4}\right)\end{array}$ & $\begin{array}{l}3.6 \times 10^{-3} \\
\left( \pm 1.5 \times 10^{-3}\right)\end{array}$ & $\begin{array}{l}2.5 \times 10^{-2} \\
\left( \pm 3.0 \times 10^{-4}\right)\end{array}$ & $\begin{array}{l}1.6 \times 10^{-2} \\
\left( \pm 1.9 \times 10^{-3}\right)\end{array}$ & $\begin{array}{l}2.1 \times 10^{-2} \\
\left( \pm 2.1 \times 10^{-3}\right)\end{array}$ & $\begin{array}{l}9.4 \times 10^{-3} \\
\left( \pm 1.8 \times 10^{-3}\right)\end{array}$ & $\begin{array}{l}1.8 \times 10^{-2} \\
\left( \pm 2.0 \times 10^{-3}\right)\end{array}$ \\
\hline $\begin{array}{l}\text { Daily } \\
\text { risks }\end{array}$ & $\begin{array}{l}2.7 \times 10^{-2} \\
\left( \pm 1.0 \times 10^{-3}\right)\end{array}$ & $\begin{array}{l}1.6 \times 10^{-2} \\
\left( \pm 2.2 \times 10^{-4}\right)\end{array}$ & $\begin{array}{l}5.4 \times 10^{-3} \\
\left( \pm 1.9 \times 10^{-3}\right)\end{array}$ & $\begin{array}{l}3.6 \times 10^{-2} \\
\left( \pm 4.7 \times 10^{-4}\right)\end{array}$ & $\begin{array}{l}2.4 \times 10^{-2} \\
\left( \pm 2.6 \times 10^{-3}\right)\end{array}$ & $\begin{array}{l}3.1 \times 10^{-2} \\
\left( \pm 2.7 \times 10^{-3}\right)\end{array}$ & $\begin{array}{l}1.4 \times 10^{-2} \\
\left( \pm 2.4 \times 10^{-3}\right)\end{array}$ & $\begin{array}{l}2.7 \times 10^{-2} \\
\left( \pm 2.6 \times 10^{-3}\right)\end{array}$ \\
\hline $\begin{array}{c}\text { Yearly } \\
\text { risks }\end{array}$ & $\begin{array}{l}1 \\
\left( \pm 5.2 \times 10^{-3}\right)\end{array}$ & $\begin{array}{l}9.9 \times 10^{-1} \\
\left( \pm 7.3 \times 10^{-3}\right)\end{array}$ & $\begin{array}{l}8.6 \times 10^{-1} \\
\left( \pm 6.1 \times 10^{-3}\right)\end{array}$ & $\begin{array}{l}1 \\
\left( \pm 4.8 \times 10^{-4}\right)\end{array}$ & $\begin{array}{l}9.9 \times 10^{-1} \\
\left( \pm 3.1 \times 10^{-3}\right)\end{array}$ & $\begin{array}{l}1 \\
\left( \pm 3.8 \times 10^{-3}\right)\end{array}$ & $\begin{array}{l}9.9 \times 10^{-1} \\
\left( \pm 5.4 \times 10^{-3}\right)\end{array}$ & $\begin{array}{l}9.9 \times 10^{-1} \\
\left( \pm 1.8 \times 10^{-3}\right)\end{array}$ \\
\hline
\end{tabular}


0.03

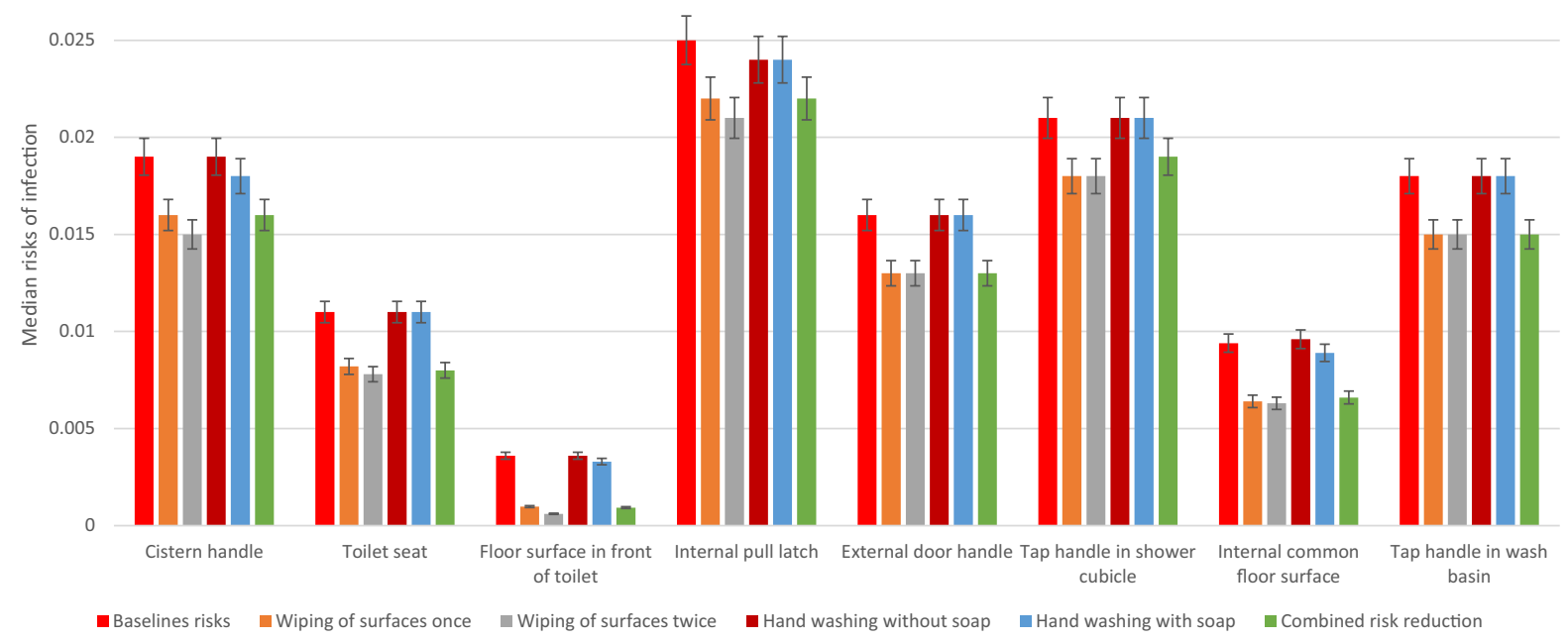

Fig. 4 Calculated median risks of infection incorporating different risk-reduction interventions

to act as possible avenues or routes of pathogen transmission. The observation that the cistern handle, floor, latch of toilet, door handle, and tap handle were the most contaminated surfaces corroborates with other studies (Abiose, 2019; De Alwis et al., 2012; Fankem et al., 2006; Flores et al., 2011; McGinnis et al., 2019; Sabra, 2013; Verani et al., 2014). For instance, the study by Fankem et al. (2006) observed that the most contaminated surfaces in public toilet facilities found in airports, bus terminals, and universities were toilet seats, sinks, floors, and napkin dispensers. However, that study represented different physical environments, where the prevalence of contamination can be expected to be much lower (3-21\%) compared to the findings in this study where all surfaces were contaminated. Furthermore, the toilet facilities in their study were in areas that perhaps had lesser user numbers or frequency of use compared to the CABs located in the informal settlements. In our study area, the CABs serve as the only source of sanitation for the inhabitants in these settlements. Sabra (2013) reported higher occurrence of contamination of contact surfaces within female public toilets, like the findings in our study (100\%). They also demonstrated that over $91 \%$ of toilet handles were contaminated.

Several reasons could account for the contamination. These include direct deposition of faeces on these surfaces, unclean hands and soil. For instance, surfaces such as the cistern handle, the tap handle, and latch of the toilet door could have been contaminated through unclean hands. A study by De
Alwis et al. (2012) observed that ntamination of door handles in male toilets were highly contaminated compared to female toilets. This was followed by a survey of the users, who reported that over $50 \%$ of the males using these toilets did not wash their hands. Therefore, unclean hands could have accounted for the high contamination rate of regularly touched surfaces. The contamination of the toilet seats and floors next to the toilets could be due to the direct deposition or aerosolization of faecal matter. Flushing of toilets has been reported to play a role in toilet seat contamination due to the generation of droplets or aerosols that may contain some faecal matter (Flores et al., 2011). Studies have shown that droplets or aerosols generated after multiple flushing could still contain bacteria, although in reduced concentrations. For instance, Johnson et al. (2017) reported a $3 \log _{10}$ reduction in bacterial indicators in the bowl water after one flush, $1-2 \log _{10}$ after two flushes, and thereafter, less than $1 \log _{10}$ reduction. These reports therefore support our hypothesis that the contamination of the toilet seats is primarily due to the presence of $E$. coli in faecal matter that is deposited either directly on these toilet seats or due to droplets or aerosols generated during flushing. One of the other most contaminated surfaces was the floor, which could be attributed to soil from footwear (Flores et al., 2011). The presence of these bacteria in the soil could be from faecal contamination or normal microflora. During the study we observed that 
children were playing on the floor within these toilet cubicles, thus highlighting a significant health risk. In addition to soil being the main source of floor contamination, it could also account for contamination of the cistern handles, in addition to unclean hands (Flores et al., 2011). This conclusion was based on the observation that some people used their feet for flushing of the toilets and the presence of a similar bacterial community on the toilet floors and the cistern handles. It has also been reported that some persons within the study area wipe faeces with their hands and smear these faeces on walls, either due to habit or religious reasons. This was corroborated by our findings, where faecal contamination on the $\mathrm{CAB}$ walls was commonly observed as shown in results above. This practice could have contributed to the contamination of the other contact surfaces. The detection of E. coli on the various contact surfaces highlights the potential risks of infection. These surfaces could, therefore, be harbouring large concentration of other potentially pathogenic microbes, as inferred from the concentration of $E$. coli on these surfaces.

Risks of infection associated with use of community ablution blocks (CABs)

The calculated risk due to contact with these surfaces is high. For instance, almost 3 people out of 100 exposed to the internal pull latch of the toilet door could be infected. This risk is for one-time use, with increasing risks when one considers the multiple uses during a day and the reliance on these facilities throughout the year. Although the risks were lower for the other surfaces, these were not statistically significant except when compared to the internal common floor. The risk of infection based on the bacterial concentration on the toilet floor in the common area was $9.7 \times 10^{-3}$ $\left( \pm 1.8 \times 10^{-3}\right)$ per person. This is much lower than the risks associated with the other seven surfaces, mainly due to the likelihood of such exposure occurring. As presented in Fig. 2, hand contact was assumed as the main route of exposure; therefore, the possibility that users of the CABs will touch the toilet floor is lesser compared to touching the other surfaces. Therefore, the potential risk calculated is less than the other contact surfaces. None the less when one considers the fact that on the average uses of the CABs will result in touching more than one surface then the risks presented in
Table 1 could be higher. For instance, on average all users of the CABs will be exposed to the external door handle of the toilet cubicle, the toilet seat, and cistern handle. If they wash their hands, the tap handle is included. Therefore, the combined risks from exposure to these multiple surfaces will be higher. The risk estimates calculated in this study are higher than the estimates reported by Ryan et al. (2014) for touch with surfaces contaminated with E. coli $0147: \mathrm{H} 7$. In that study a single touch risks of $1.5 \times 10^{-4}$ was reported. The risk estimates in this study are considerably higher than the tolerable risk figure of 1 in 1 million $\left(10^{-6}\right)$ recommended by Ryan et al. (2014) for touch with contaminated surfaces. This calls for the implementation of risk-reduction measures.

The risks of infection when simple mitigation measures such as thorough cleaning of the surfaces and washing of hands with and without soap are implemented were calculated to be lower. A simple wipe of surfaces with soap could lead to about $1 \log _{10}$ bacterial reduction on surfaces (Tuladhar et al., 2012). A second wipe achieved a further 1-3 $\log _{10}$ reduction. Therefore, regular wiping on these surfaces by either the users or caretakers could potentially reduce the contaminations further. This will subsequently lead to lower risks of infections. A further reduction in the risks is achievable if the users of these facilities washed their hands either with or without soap. Incorporating these possible risk-reduction strategies resulted in a reduced risk as presented in Fig. 4. The most important or significant risk-reduction measure among those considered in this study is wiping the contact surfaces especially twice. For instance, the risk of infection due to contact with the internal pull latch of the toilet door after wiping once was reduced to about two out of a 100 people infected $\left(2.2 \times 10^{-2}\left( \pm 3.1 \times 10^{-4}\right)\right)$ per person per one-time exposure (Fig. 4; Table S3). Although hand washing was observed to possibly lead to risk reduction, the estimates achieved in this study indicate that this is not the most significant intervention. The reduction in pathogen concentration when hands are washed with soap was assumed to be only $1.7( \pm 0.8) \log _{10}$ (Jensen et al., 2015). This therefore could be the main reason for the little effect of hand washing on its own. It must also be noted that none of the risk-reduction options modelled in this study could reduce the risks to the tolerable/acceptable risks estimate of $\left(10^{-6}\right)$ recommended by Ryan et al. (2014).

The detection of E. coli, an indicator for faecal pollution, and the associated risks estimated shows the potential for other pathogens on these surfaces. $E$. 
coli is widely used and accepted as a faecal indicator organism (McLellan \& Eren, 2014; Wen et al., 2020). However, the utility of E. coli as an indicator for determination of risk of infection with other pathogens has been questioned due to reported differences in survival and infectivity. For instance, most STHs require some period of latency before becoming infectious. Ascaris spp. ova/eggs, as an example, require a latency period of 2-4 weeks at temperatures between 15 and $38{ }^{\circ} \mathrm{C}$ before becoming infectious (Bogitsh et al., 2012). Therefore, although the detection of $E$. coli on the contact surfaces gives an indication of the potential risks of infection for other faecal pathogens, it must be noted that it may either over- or underestimate the risks.

\section{Conclusions}

This study shows that contamination of key contact surfaces within shared sanitation facilities is a common occurrence. Contamination could be due to several factors pertaining to hygiene practices and general habits of the users of these facilities including direct deposition, aerosol generation from toilet flushing, unclean hands, and soil from footwear. Contamination of key contact surfaces poses potentially higher risks of infection, with almost everyone at risk of infection over the course of a year due to reliance on these facilities. The incorporation of risk-reduction strategies, such as wiping of surfaces and washing of hands, has the potential to reduce infection risks; however, the use of these CABs still poses significant health risks. Furthermore, this study has shown that QMRA can be adapted to present a powerful tool for measuring the potential risks associated with the use of shared sanitation facilities.

Therefore, to reduce the risks associated with the use of CABs within the study area, the following recommendations are made:

1. Effective cleaning of key contact surfaces: Cleaning of key contact surfaces could potentially reduce the concentration of potential pathogens and associated risks of infection.

2. Re-training of caretakers: To achieve effective cleaning, re-training of caretakers is suggested. Focus on the importance of cleaning key surfaces that are regularly touched by users should be considered.
3. Improved hygiene of users: There is the need for public education among users of the CABs to encourage hygiene practices such as washing of hands, with or without soap, to reduce contamination of other surfaces. The provision of soap for handwashing could potentially reduce the prevalence of contamination even further.

4. Provision of refuse bins at each CAB: Regular waste collection will deter littering both internally and externally of the facility.

5. Community education: The contamination levels within the CABs could also be considerably reduced if the community members are educated on the consequences of contamination of these areas and how to ensure proper hygiene practices. This could be in the form or posters and audiovisual materials.

\section{Study limitations}

Despite the significant findings made in this study, some limitations were identified. These limitations include the following:

1. Sampling frequency and sampling points: This study was impacted by the COVID-19 pandemic, limiting the ability to sample more frequently and include more sampling points. Additionally, lockdown restrictions were imposed in the city of Durban, which affected the use of the CABs within the study locations. These limitations have the potential to affect the concentration of E. coli, with subsequent impact of the risk estimations.

2. Probabilistic risk estimations: The practice of estimating risks based on probability introduces a level of uncertainty which could be a limitation with respect to the reliability of the data. In this study, variability in E. coli concentrations was accounted for using Monte Carlo simulations with up to 10,000 iterations. However, it must be acknowledged that the use of probabilistic risk estimations could be a limitation.

3. Pathogenic E. coli concentration: In this study the concentration of pathogenic E. coli was estimated based on the percentage of total $E$. coli that is reported to be pathogenic. This could lead to 
either under- or overestimation of the concentration of pathogenic $E$. coli in the study area, which could have effect of the level of risks estimated.

\section{Implications of findings}

The findings of this study have implications for future practice in relation to sanitation delivery. Evaluation of sanitation facilities has largely focused on the use of these facilities and their physical state. However, this study presented an approach that can be used to estimate risks associated with the use of these facilities. This approach could be added to the evaluation of sanitation facilities to provide an input on the potential risks. This would be very instrumental in ensuring that sanitation facilities do not become hotspots for disease transmission.

Author contribution P.S. Ramlal, T-A Stenström, and I.D. Amoah: conceptualization. P.S. Ramlal and I.D. Amoah: methodology, field work, data curation, software, validation, formal analysis, writing of original draft, visualization. J. Lin, C.A. Buckley, and T-A Stenström: supervision, review, and editing.

Data availability All data generated or analysed during this study are included in this published article.

\section{Declarations}

Competing interests The authors declare no competing interests.

\section{References}

Abid, A. J., \& AL-zuwainy, S. J. (2015). Using of astA and uidA genes characterization in detection of Escherichia coli prevalence from human gallstone. International Journal of Science and Research, 3(8), 935-939. Paper ID: 020141233.

Abiose, O. F. (2019). Bacterial contamination of selected public toilet door handles within Adekunle Ajasin University Campus, Akungba-Akoko, Ondo State, Nigeria. International Journal of Sciences: Basic and Applied Research, 43(1), 76-86.

Ahmed, D., Hoque, A., Elahi, M. S. B., Endtz, H. P., \& Hossain, M. A. (2012). Bacterial aetiology of diarrhoeal diseases and antimicrobial resistance in Dhaka, Bangladesh, 20052008. Epidemiology and Infection, 140(9), 1678-1684. https://doi.org/10.1017/S0950268811002135
Alsallaiy, I., Dawson, P., Han, I., \& Martinez-Dawson, R. (2016). Recovery, survival and transfer of bacteria on restaurant menus. Journal of Food Safety, 36(1), 52-61. https://doi.org/10.1111/jfs. 12212

Baker, K. K., O’Reilly, C. E., Levine, M. M., Kotloff, K. L., Nataro, J. P., Ayers, T. L., Farag, T. H., Nasrin, D., Blackwelder, W. C., Wu, Y., Alonso, P. L., Breiman, R. F., Omare, R., Faruque, A. S. G., Das, S. K., Ahmed, S., Saha, D., Sow, S. O., Sur, D., Zaidi, A. K. M., Quadri, F., \& Mintz, E. D. (2016). Sanitation and hygiene-specific risk factors for moderate-to-severe diarrhea in young children in the global enteric multicenter study, 2007-2011: Case-control study. PLOS Medicine, 13(5), e1002010. https://doi.org/10.1371/journal.pmed.1002010

Barker, J., \& Bloomfield, S. F. (2000). Survival of Salmonella in bathrooms and toilets in domestic homes following salmonellosis. Journal of Applied Microbiology, 89(1), 137144. https://doi.org/10.1046/j.1365-2672.2000.01091.x

Bogitsh, B. J., Carter, C. E., \& Oeltmann, T. N. (2012). General characteristics of the Nematoda (chapter 15), intestinal nematodes (chapter 16). In Human Parasitology (pp 269-345). Academic Press, UK.

Bohnert, K., Chard, A. N., Mwaki, A., Kirby, A. E., Muga, R., Nagel, C. L., Thomas, E. A., \& Freeman, M. C. (2016). Comparing sanitation delivery modalities in urban informal settlement schools: A randomized trial in Nairobi, Kenya. International Journal of Environmental Research and Public Health, 13(12), 1189. https://doi.org/10.3390/ ijerph13121189

Busquet, M. M. (2015). The practice of sharing sanitation facilities. A case study on shared sanitation facilities as sustainable form of access to sanitation in the West Nile Region, Uganda (Master's thesis). Utrecht University, Netherlands.

Carducci, A., Donzelli, G., Cioni, L., \& Verani, M. (2016). Quantitative microbial risk assessment in occupational settings applied to the airborne human adenovirus infection. International Journal of Environmental Research and Public Health, 13(7), 733. https://doi.org/10.3390/ ijerph13070733

Crocker, J., \& Bartram, J. (2016). Interpreting the Global Enteric Multicenter Study (GEMS) findings on sanitation, hygiene and diarrhea. PLOS Medicine, 13(5), e1002011. https://doi.org/10.1371/journal.pmed.1002011

Curtis, V., Biran, A., Deverell, K., Hughes, C., Bellamy, K., \& Drasar, B. (2003). Hygiene in the home: Relating bugs and behaviour. Social Science and Medicine, 57(4), 657672. https://doi.org/10.1016/s0277-9536(02)00409-4

De Alwis, W. R., Pakirisamy, P., Wai San, L., \& Xiaofen, E. C. (2012). A study on hand contamination and hand washing practices among medical students. ISRN Public Health, 2012, Article ID 251483. https://doi.org/10.5402/2012/251483

Dinno, A. (2015). Nonparametric pairwise multiple comparisons in independent groups using Dunn's test. The Stata Journal, 15(1), 292-300. https://doi.org/10.1177/1536867X1501500117

Ezzat, S. M. (2020). Applying quantitative microbial risk assessment model in developing appropriate standards for irrigation water. Integrated Environmental Assessment and Management, 16(3), 353-361. https://doi.org/10. 1002/ieam.4232 
Fankem, S., Kennedy, D., Enriquez, C., \& Gerba, C. (2006). Assessment of enteric pathogen exposure in public toilets. Epidemiology, 17(6), S457.

Fenn, B., Bulti, A. T., Nduna, T., Duffield, A., \& Watson, F. (2012). An evaluation of an operations research project to reduce childhood stunting in a food-insecure area in Ethiopia. Public Health Nutrition, 15(9), 1746-1754. https:// doi.org/10.1017/S1368980012001115

Flores, G. E., Bates, S. T., Knights, D., Lauber, C. L., Stombaugh, J., Knight, R., \& Fierer, N. (2011). Microbial biogeography of public restroom surfaces. PLOS ONE, 6(11), e28132. https://doi.org/10.1371/journal.pone.0028132

Garn, J. V., Sclar, G. D., Freeman, M. C., Penakalapati, G., Alexander, K. T., Brooks, P., Rehfuess, E. A., Boisson, S., Medlicott, K. O., \& Clasen, T. F. (2017). The impact of sanitation interventions on latrine coverage and latrine use: A systematic review and meta-analysis. International Journal of Hygiene and Environmental Health, 220 $2 \mathrm{Pt}$ B), 329-340. https://doi.org/10.1016/j.ijheh.2016.10.001

George, J., Divya, L., \& Suriyanarayanan, S. (2013). Quantitative microbial risk assessment in the management of Escherichia coli strains via drinking water. Journal of Environmental Research and Development, 8(1), 60-68.

Gerhardts, A., Hammer, T. R., Balluff, C., Mucha, H., \& Hoefer, D. (2012). A model of the transmission of micro-organisms in a public setting and its correlation to pathogen infection risks. Journal of Applied Microbiology, 112(3), 614-621. https://doi.org/10.1111/j.1365-2672.2012.05234.x

Girardi, V., Mena, K. D., Albino, S. M., Demoliner, M., Gularte, J. S., de Souza, F. G., Rigotto, C., Quevedo, D. M., Schneider, V. E., Paesi, S. O., Tarwater, P. M., \& Spilki, F. R. (2019). Microbial risk assessment in recreational freshwaters from southern Brazil. Science of the Total Environment, 651(Pt 1), 298-308. https://doi.org/10. 1016/j.scitotenv.2018.09.177

Guerrant, R. L., DeBoer, M. D., Moore, S. R., Scharf, R. J., \& Lima, A. A. M. (2013). The impoverished gut-A triple burden of diarrhoea, stunting and chronic disease. Nature Reviews Gastroenterology Hepatology, 10(4), 220-224. https://doi.org/10.1038/nrgastro.2012.239

Gularte, J. S., Girardi, V., Demoliner, M., de Souza, F. G., Filippi, M., Eisen, A. K. A., Mena, K. D., de Quevedo, D. M., Rigotto, C., de Barros, M. P., \& Spilki, F. R. (2019). Human mastadenovirus in water, sediment, sea surface microlayer, and bivalve mollusk from southern Brazilian beaches. Marine Pollution Bulletin, 142, 335-349. https:// doi.org/10.1016/j.marpolbul.2018.12.046

Günther, I., Niwagaba, C. B., Lüthi, C., Horst, A., Mosler, H. J., \& Tumwebaze, I. K. (2012). When is shared sanitation improved sanitation?-The correlation between number of users and toilet hygiene. MPRA Paper No. 45830, Munich, Germany.

Haas, C., Rose, J., \& Gerba, C. (2014). Quantitative microbial risk assessment (2nd ed.). John Wiley and Sons.

Heijnen, M., Cumming, O., Peletz, R., Chan, G. K. S., Brown, J., Baker, K., \& Clasen, T. (2014). Shared sanitation versus individual household latrines: A systematic review of health outcomes. PLoS One, 9(4), e93300. https://doi.org/ 10.1371/journal.pone.0093300

Howard, G., Pedley, S., \& Tibatemwa, S. (2006). Quantitative microbial risk assessment to estimate health risks attributable to water supply: Can the technique be applied in developing countries with limited data? Journal of Water and Health, 4(1), 49-65. PMID: 16604838.

Jensen, D. A., Danyluk, M. D., Harris, L. J., \& Schaffner, D. W. (2015). Quantifying the effect of hand wash duration, soap use, ground beef debris, and drying methods on the removal of Enterobacter aerogenes on hands. Journal of Food Protection, 78(4), 685-690. https://doi.org/10.4315/ 0362-028X.JFP-14-245

Johnson, D. L., Lynch, R. A., Villanella, S. M., Jones, J. F., Fang, H., Mead, K. R., \& Hirst, D. V. (2017). Persistence of bowl water contamination during sequential flushes of contaminated toilets. Journal of Environmental Health, 80(3), 34-49. PMID: 29651169.

Kagan, L. J., Aiello, A. E., \& Larson, E. (2002). The role of the home environment in the transmission of infectious diseases. Journal of Community Health, 27(4), 247-267. https://doi.org/10.1023/a:1016378226861

Katukiza, A. Y., Ronteltap, M., Niwagaba, C. B., Foppen, J. W. A., Kansiime, F., \& Lens, P. N. L. (2012). Sustainable sanitation technology options for urban slums. Biotechnology Advances, 30(2012), 964-978. https://doi.org/10.1016/j. biotechadv.2012.02.007

Kay, D., Watkins, J., \& Fewtrell, L. (2006). An evaluation of public health issues associated with, or arising from, drainage-based infection spread. Building Services Engineering Research and Technology, 27(2), 119-125. https://doi.org/ 10.1191/0143624406bt146oa

Kwiringira, J. (2017). Barriers to shared sanitation cleaning and maintenance in Kampala Slums, Uganda. In Local action with international cooperation to improve and sustain water, sanitation and hygiene (WASH) services: Proceedings of the 40th WEDC International Conference, Loughborough, UK (pp. 24-28). cc WEDC, Loughborough University.

Lange, B., Strathmann, M., \& Oßmer, R. (2013). Performance validation of chromogenic coliform agar for the enumeration of Escherichia coli and coliform bacteria. Letters in Applied Microbiology, 57, 547-553. https://doi.org/10. 1111/lam.12147

Lupindu, A. M. (2017). Isolation and characterization of Escherichia coli from animals, humans, and environment, In A. Samie (Ed.), Escherichia coli - Recent advances on physiology, pathogenesis and biotechnological applications, (pp.187-206). Intech Open Limited, London. https://doi.org/10.5772/67390

Machdar, E., van der Steen, N. P., Raschid-Sally, L., \& Lens, P. N. L. (2013). Application of quantitative microbial risk assessment to analyze the public health risk from poor drinking water quality in a low income area in Accra, Ghana. Science of the Total Environment, 449, 134-142. https://doi.org/10.1016/j.scitotenv.2013.01.048

McGinnis, S., Marini, D., Amatya, P., \& Murphy, H. M. (2019). Bacterial contamination on latrine surfaces in community and household latrines in Kathmandu. Nepal. International Journal of Environmental Research and Public Health, 16(2), 257. https://doi.org/10.3390/ijerph16020257

McLellan, S. L., \& Eren, A. M. (2014). Discovering new indicators of fecal pollution. Trends in Microbiology, 22(12), 697-706. https://doi.org/10.1016/j.tim.2014.08.002

Mpotane, T., Ntswabule, V., McPherson, C., \& Botes, E. (2013). The role of toilet hygiene in transmission of vaginal and 
urinary tract infections in Huis Welgemoed. CUT Campus. Interim: Interdisciplinary Journal, 12(1), 26-31. ISSN 1684-498X.

Neely, A. N., \& Maley, M. P. (2000). Survival of enterococci and staphylococci on hospital fabrics and plastic. Journal of Clinical Microbiology, 38(2), 724-726. https://doi.org/ 10.1128/JCM.38.2.724-726.2000

Park, G. W., Chhabra, P., \& Vinjé, J. (2017). Swab sampling method for the detection of human norovirus on surfaces. Journal of Visualized Experiments, 6(120), e55205. https://doi.org/10.3791/55205

Patil, S. R., Arnold, B. F., Salvatore, A. L., Briceno, B., Ganguly, S., Colford, J. M., Jr., \& Gertler, P. J. (2014). The effect of India's total sanitation campaign on defecation behaviors and child health in rural Madhya Pradesh: A cluster randomized controlled trial. PLOS Medicine, 11(8), e1001709. https://doi.org/10.1371/journal.pmed.1001709

Petterson, S. R., \& Ashbolt, N. J. (2016). QMRA and water safety management: Review of application in drinking water systems. Journal of Water and Health, 14(4), 571589. https://doi.org/10.2166/wh.2016.262

Pickering, A. J., Djebbari, H., Lopez, C., Coulibaly, M., \& Alzua, M. L. (2015). Effect of a community-led sanitation intervention on child diarrhoea and child growth in rural Mali: A cluster-randomised controlled trial. Lancet Global Health, 3(11), e701-e711. https://doi.org/10.1016/ S2214-109X(15)00144-8

Rah, J. H., Cronin, A. A., Badgaiyan, B., Aguayo, V. M., Coates, S., \& Ahmed, S. (2015). Household sanitation and personal hygiene practices are associated with child stunting in rural India: A cross-sectional analysis of surveys. British Medical Journal Open, 5(2), e005180. https://doi. org/10.1136/bmjopen-2014-005180

Ramlal, P. S., Stenström, T. A., Munien, S., Amoah, I. D., Buckley, C. A., \& Sershen. (2019). Relationships between shared sanitation facilities and diarrhoeal and soil-transmitted helminth infections: An analytical review. Journal of Water, Sanitation and Hygiene for Development, 9(2), 198-209. https://doi.org/ 10.2166/washdev.2019.180

Ryan, M. O., Haas, C. N., Gurian, P. L., Gerba, C. P., Panzl, B. M., \& Rose, J. B. (2014). Application of quantitative microbial risk assessment for selection of microbial reduction targets for hard surface disinfectants. American Journal of Infection Control, 42(11), 1165-1172. https:// doi.org/10.1016/j.ajic.2014.07.024

Sabra, S. M. M. (2013). Bacterial public health hazard in the public female restrooms at Taif. KSA. Middle-East Journal of Scientific Research., 14(1), 63-68. https://doi.org/ 10.5829/idosi.mejsr.2013.14.1.7326

Sakaji, R. H., \& Funamizu N. (1998). Microbial risk assessment and its role in the development of wastewater reclamation policy. In T. Asano (Ed.), Wastewater reclamation and reuse (vol 10, pp. 705-756). CRC Press, Boca Raton.

Schouten, M. A. C., \& Mathenge, R. W. (2010). Communal sanitation alternatives for slums: A case study of Kibera, Kenya. Physics and Chemistry of the Earth, Parts $a / b / c$, 35(13-14), 815-822. https://doi.org/10.1016/j.pce.2010. 07.002

Tuladhar, E., Hazeleger, W. C., Koopmans, M., Zwietering, M. H., Beumer, R. R., \& Duizer, E. (2012). Residual viral and bacterial contamination of surfaces after cleaning and disinfection. Applied and Environmental Microbiology, 78(21), 7769-7775. https://doi.org/10.1128/AEM. 02144-12

Tumwebaze, I. K., \& Mosler, H. J. (2015). Effectiveness of group discussions and commitment in improving cleaning behaviour of shared sanitation users in Kampala, Uganda slums. Social Science and Medicine, 147, 72-79. https:// doi.org/10.1016/j.socscimed.2015.10.059

Verani, M., Bigazzi, R., \& Carducci, A. (2014). Viral contamination of aerosol and surfaces through toilet use in health care and other settings. American Journal of Infection Control, 42(7), 758-762. https://doi.org/10.1016/j.ajic.2014.03.026

Wen, X., Chen, F., Lin, Y., Zhu, H., Yuan, F., Kuang, D., Jia, Z., \& Yuan, Z. (2020). Microbial indicators and their use for monitoring drinking water quality-A review. Sustainability, 12(6), 2249. https://doi.org/10.3390/su12062249

Publisher's Note Springer Nature remains neutral with regard to jurisdictional claims in published maps and institutional affiliations. 